\title{
Exercise tolerance in asymptomatic patients with moderate-severe valvular heart disease and preserved ejection fraction
}

Schulz Olaf', Brala Debora', Bensch Ricarda ${ }^{1}$, Berghöfer Gunnar ${ }^{1}$, Krämer Jochen ${ }^{1}$, Ingolf Schimke ${ }^{2}$, Martin Halle ${ }^{3}$, Allan Jaffe ${ }^{4}$

\author{
IInterventional Cardiology Spandau, Berlin, Germany \\ 2Department of Cardiology, Charité Universitätsmedizin Berlin, Germany \\ ${ }^{3}$ Department of Prevention and Sports Medicine, Technische Universität Munich, \\ Germany \\ ${ }^{4}$ Mayo Clinic and Medical School, Rochester, MN, USA
}

Submitted: 31 August 2012

Accepted: 20 November 2012

Arch Med Sci 2012; 8, 6: 1018-1026

DOI: 10.5114/aoms.2012.32409

Copyright $\odot 2012$ Termedia \& Banach

\begin{abstract}
Introduction: For asymptomatic patients with moderate-severe valvular heart disease, in whom symptoms may be obscured, objective exercise tolerance measures are warranted for decisions concerning physical activities and surgical treatment.

Material and methods: We compared 61 patients (39 with aortic stenosis, 22 with aortic or mitral regurgitation) to 23 controls without valvular heart disease but with indications for stress testing. All participants underwent cardiopulmonary function testing and dobutamine stress echocardiography. Blood was drawn before as well as after bicycle stress to assess high-sensitivity cardiac troponin $\mathrm{T}$ (hscTnT). Patients who underwent surgery were re-evaluated $1.5 \pm 0.9$ years after the operation.

Results: Conventional bicycle test following guideline criteria revealed a pathologic result in $26 \%$ of the patients, whereas spiroergometry showed an objectively reduced exercise tolerance in $59 \%$, reaching a prognostically relevant feature in $39 \%$. Stress echocardiography detected a reduced systolic reserve in $33 \%$ and elevated filling pressures in $62 \%$. These abnormalities were significantly less present in the control group (4, 17, 9, 9, 4\% respectively, $p<0.05$ each). Baseline hscTnT detected patients with the prognostically important feature of reduced exercise tolerance (area under the curve 0.689 (95\% Cl: 0.546-0.831), $p=0.015)$. Objective preoperative exercise tolerance predicted sustained cardiocirculatory and myocardial dysfunction postoperatively.

Conclusions: Cardiopulmonary function testing and dobutamine stress echocardiography identify exercise intolerance in patients with asymptomatic valvular heart disease beyond stress-test criteria recommended in recent guidelines. High-sensitivity cardiac troponin I may be of additional value. Results of these tests presage post-operative function.
\end{abstract}

Key words: valvular heart disease, exercise tolerance, spiroergometry, troponin.

\section{Introduction}

In patients with higher-degree valvular heart disease (VHD), symptoms determine prognosis, e.g. the timing of surgery, but symptoms may be obscured by comorbidities. Thus, a stress test to objectivate exercise tol-

\author{
Corresponding author: \\ Schulz Olaf MD \\ Interventionelle Kardiologie \\ Spandau \\ Neuendorfer Str. 70 \\ 13585 Berlin \\ Phone: +49 303039800 \\ E-mail: \\ oschulz@cath-lab-spandau.de
}


erance in patients reporting to be asymptomatic is recommended [1].

The aim of our study was to investigate whether spiroergometry, dobutamine stress echocardiography as well as a biomarker of myocardial injury are more sensitive than recommended stress test criteria, achievable from a conventional bicycle test. Patients who underwent surgery were investigated postoperatively as well to describe whether optimized timing of surgery by consideration of objective exercise intolerance is potentially able to prevent also postoperatively continuing remodeling and reduced functional outcome.

\section{Material and methods}

\section{Patients}

The inclusion and exclusion criteria for this study have been reported in detail recently [2]. We consecutively included patients with VHD and preserved left ventricular ejection fractions (EF; $\geq 50 \%$ ) who denied cardiovascular symptoms. Patients with aortic stenosis required a mean pressure gradient $>35 \mathrm{~mm} \mathrm{Hg}$ or an aortic valve area $<1 \mathrm{~cm}^{2}$. For patients with aortic or mitral regurgitation, the severity of regurgitation required was $>$ grade 2 established by a comprehensive evaluation of color and conventional Doppler criteria. Exclusion criteria were an indication for surgical treatment of VHD [1], concomitant additional valvular lesions $>$ grade 2 , significant coronary artery disease, atrial fibrillation, an inability to perform stress testing, or other severe noncardiac comorbidities. In the control group we included subjects referred for stress testing due to suspicious symptoms. However, serious, exercise-limiting diseases (e.g. VHD, myocardial ischemia, reduced $\mathrm{EF}(<50 \%)$ or myocarditis) could be excluded. All subjects provided written informed consent. The local ethics committee approved the study.

All patients and controls underwent a double stress protocol including a symptom-limited semisupine bicycle exercise test with assessment of cardiopulmonary function and a dobutamine-stress echocardiogram stepwise to a maximum heart rate of $120 /$ min on separate days within 1 week.

\section{Stress tests}

Cardiopulmonary function analysis was performed by using a computerized breath-by-breath analyzer QuarkPFT ${ }^{\circledR}$ (Cosmed, Rome, Italy). Patients were exercised until symptoms or exhaustion or to at least a respiratory quotient of 1.1. Twelve-lead ECG was monitored during testing and ST-segment analysis was performed by signal averaging using the software Cardiosoft ${ }^{\circledR}$ (GE, Fairfield, Connecticut). Blood pressure was measured at each exercise level. Anaerobic threshold was assessed using graphs 5, 6, 8 and 9 from the Wasserman plot, with preference to the $\mathrm{V}$ slope (plot 5). $\mathrm{O}_{2}$ consumption was estimated at peak exercise $\left(\mathrm{VO}_{2}\right.$ peak) and at the anaerobic threshold $\left(\mathrm{VO}_{2} \mathrm{AT}\right)$. The percentage of $\mathrm{VO}_{2}$ peak to the predicted age and gender was determined $\left(\mathrm{VO}_{2} \%\right.$ pred) by nomogram [3]. The slope of the ratio of ventilation to carbon oxide production (VE/VCO 2 slope) was assessed based on established criteria [4].

Echocardiographic measurements were performed on a Vivid $5^{\circledR}$ ultrasound machine (GE Healthcare, Milwaukee, WI) according to guidelines [5]. Left ventricular mass was estimated in accordance with [6]. Ejection fraction was assessed visually and by the Simpson method. For further analysis, visually assessed values were used.

Conventional PW tissue Doppler measures of systole $\left(S^{\prime}\right)$ and diastole ( $E^{\prime}$ and $A^{\prime}$ ) were derived from the septal and lateral border of the mitral annulus. Aortic valve area was calculated by continuity equation. Transmitral inflow E/ E' [7] and E/flow propagation velocity [8] were determined to estimate left ventricular filling pressure. Doppler parameters were acquired by averaging data from 3 and flow propagation velocity from 5 cardiac cycles. Parameters were indexed to body surface area, where appropriate. During dobutamine stress, left ventricular function was assessed at each stress level. At peak heart rate, all echocardiographic parameters were measured repeatedly.

\section{Measurement of high-sensitivity cardiac troponin T (hscTnT)}

Blood was drawn before and $3 \mathrm{~h}$ and/or $5 \mathrm{~h}$ after bicycle exercise. We measured hscTnT with the Elecsys-2010 ${ }^{\circledR}$ analyzer, Roche Diagnostics, Mannheim, Germany (limit of the blank $3 \mathrm{pg} / \mathrm{ml}$, the $99^{\text {th }}$ percentile and $10 \%$ coefficient of variation $13 \mathrm{pg} / \mathrm{ml}$ ). Baseline and the latest post-stress values were presented. For values below the limit $(<3 \mathrm{pg} / \mathrm{ml}$ ) we assumed a value of $0.01 \mathrm{pg} / \mathrm{ml}$ to avoid exclusion during log-transformation.

\section{Definitions of stress response for all patients}

A guideline-related positive test (GRPT) was considered if one of the parameters mentioned in recent recommendations such as symptoms, an inadequate blood pressure response, complex ventricular arrhythmia or $>0.2 \mathrm{mV}$ ST depression occurred during bicycle stress [9]. Reduced exercise tolerance (RET) was defined when $\mathrm{VO}_{2}$ peak was $<80 \%$ of predicted [3]. A prognostically relevant feature of reduced exercise tolerance (PRET) was diagnosed if $\mathrm{VO}_{2}$ peak, $\mathrm{VO}_{2} \mathrm{AT}$ or $\mathrm{VE} / \mathrm{VCO}_{2}$ slope values reached values associated with adverse outcomes in heart failure (< 14 [10], < 11 [11], > 33 [12]). Reduced systolic reserve was considered present if 
the increase in EF after dobutamine was $<10 \%$ $[13,14]$. E/E' septal and lateral as well as E/flow propagation velocity were defined as elevated if they were $>15$ [7], > 10 [15] and > 1.5 [8]. An elevated filling pressure was diagnosed if two of these were elevated.

\section{Postoperative follow-up}

Patients who underwent surgery underwent repeated echocardiography and spiroergometry postoperatively as soon as they perceived that their cardiopulmonary function was no longer affected by surgery.

\section{Statistical analysis}

SPSS $13.0^{\circledR}$ (SPSS Institute Inc., Chicago II.) and SAS $9.2^{\circledR}$ (SAS Institute Inc., Cary, NC) programs were used. Reference parameters are reported as mean \pm SD. Biomarker data are presented as median and interquartile ranges. For statistical calculations log10-transformed values were used. Differences between groups are calculated by unpaired $t$ test for continuous variables. Fisher's exact test was used in cross-table analysis for categorical variables. Differences between measured points before and after exercise, and after surgery respectively, were analyzed by the Wilcoxon signed rank test. Associations between variables of exercise tolerance and hscTnT as well as with postoperative outcome were tested by linear (for continuous) and logistic (for categorical dependent variables) backward regression analysis. Age, gender, creatinine, hscTnT, contractile reserve, filling pressure (or alternatively in different models $\mathrm{E}$ or $\mathrm{E}^{\prime}$ ) and $\mathrm{VO}_{2} \%$ pred (or alternatively PRET) were used as independent variables.

A receiver-operator characteristic curve was constructed for hscTnT and exercise tolerance parameters.

\section{Results}

From 76 screened patients with valvular heart disease 61 could be included. Reasons for not including/terminating the study were: 5 patients refused, 1 patient moved. Clinical reasons were detection of coronary artery disease $(n=5)$, reevaluation of symptoms, development of atrial fibrillation shortly after inclusion, report of a psychiatric disease by the general practitioner, not ultimate exclusion of myocarditis (each $n=1$ ).

All participants underwent the double-stress protocol without any complications. Baseline characteristics of the population and echocardiographic values are shown in Table I.

Hemodynamics during bicycle stress and dobutamine stress echocardiography are tabulated in Tables II and III. Due to the restrictions in our dobu- tamine echocardiographic protocol recommended by the ethical review board, patients with VHD reached a lower heart rate than controls. All other hemodynamic parameters were comparable.

\section{Bicycle stress test and exercise capacity}

During bicycle stress testing, 16 patients $(26.2 \%$ of the VHD group) had a GRPT: 13 (21.3\%) patients endorsed dyspnea during bicycle stress testing. No patient reported angina or dizziness. Seven patients manifested significant ST depression. No complex arrhythmias or abnormal arterial pressure responses occurred. Amongst controls, only one patient reported dyspnea. The occurrence of GRPT was higher in VHD patients $(p=0.0320)$, particularly in those with aortic stenosis ( $p=0.0235)$.

Patients with VHD were able to climb one flight of stairs fewer than controls. Objectively, they achieved a 30 Ws lower level during bicycle stress ( $p<0.05$ for both). During cardiopulmonary exercise (Table II), a respiratory quotient of $1.22 \pm 0.16$ was reached. Reduced exercise tolerance occurred in $59 \%$ of patients with VHD. In $39.3 \%$ of patients the reduction of exercise tolerance reached the range associated with poorer outcomes (PRET group) [10-12].

\section{Dobutamine stress, contractile reserve and filling pressures}

Assessment of systolic reserve and left ventricular filling pressures by stress echocardiography are tabulated in Table III. Sixty-two percent of VHD patients met at least two of three criteria for prognostic elevations of left ventricular filling pressures $[7,8,15]$ before dobutamine and $36.7 \%$ after. Thirty-three percent of patients with VHD and $8.7 \%$ of controls lacked systolic reserve.

\section{Prognostically relevant reduction in exercise tolerance (PRET) and hscTnT}

Patients with PRET $(n=37)$ were older $(67 \pm 12$ years vs. $59 \pm 15$ years; $p=0.0198)$, more often female ( $46 \%$ vs. $22 \%$; $p=0.0132$ ), and more often received vasodilators ( $54 \%$ vs. $16 \% ; p=0.0039$ ). E/flow propagation velocity after dobutamine was lower ( $1.4 \pm 0.4$ vs. $1.8 \pm 0.6$; $p=0.0106)$, which was associated with lower $\mathrm{E}$ after dobutamine $(95.7 \pm 23.9 \mathrm{~cm} / \mathrm{s}$ vs. $113.2 \pm 32.6 \mathrm{~cm} / \mathrm{s} ; p=0.0187)$. Flow propagation was not different. $E^{\prime}$ septal was lower $(6.4 \pm 1.5 \mathrm{~cm} / \mathrm{s}$ vs. $7.6 \pm 3.0 \mathrm{~cm} / \mathrm{s} ; p=0.0338)$ in PRET, too. The type of VHD did not differ significantly between patients with or without PRET. However, $46 \%$ of patients with aortic stenosis, but only $27 \%$ of patients with regurgitation, belonged to the PRET group $(p=0.18)$. There were no other differences in measures of systolic reserve or dias- 
Table I. Baseline characteristics

\begin{tabular}{|c|c|c|c|c|}
\hline Parameters & Controls & VHD & Aortic stenosis & Regurgitation \\
\hline$n$ & 23 & 61 & 39 & 22 \\
\hline Male (\%) & 48 & 66 & 64 & 64 \\
\hline Age [years] & $56 \pm 11$ & $62 \pm 15^{*}$ & $67 \pm 11^{\ddagger}$ & $54 \pm 17$ \\
\hline Body mass index $\left[\mathrm{kg} / \mathrm{m}^{2}\right]$ & $24.7 \pm 2.9$ & $26.9 \pm 3.4^{\dagger}$ & $27.5 \pm 3.6^{\dagger}$ & $25.7 \pm 2.7$ \\
\hline Creatinine $[\mu \mathrm{mol} / \mathrm{l}]$ & $73.0 \pm 13.5$ & $82.9 \pm 16.6^{\dagger}$ & $79.2 \pm 14.1$ & $86.2 \pm 19.0^{\dagger}$ \\
\hline \multicolumn{5}{|l|}{ Concomitant diseases, $n$ : } \\
\hline Arterial hypertension & 9 & 30 & 23 & 7 \\
\hline Diabetes mellitus & 0 & 5 & 2 & 3 \\
\hline \multicolumn{5}{|l|}{ Medication, $n$ : } \\
\hline ACE inhibitors/ARB & 4 & $46^{\ddagger}$ & $27^{\ddagger}$ & $19^{\ddagger}$ \\
\hline$\beta$-Blockers & 10 & 27 & 16 & 11 \\
\hline Calcium channel blockers/nitrates & 1 & $19^{\dagger}$ & $13^{\dagger}$ & $6^{*}$ \\
\hline Diuretics & 0 & $29^{\ddagger}$ & $15^{\ddagger}$ & $14^{\ddagger}$ \\
\hline \multicolumn{5}{|l|}{ Echocardiography: } \\
\hline Left ventricular ejection fraction [\%] & $65.5 \pm 4.4$ & $65.5 \pm 5.7$ & $67.9 \pm 5.0$ & $61.7 \pm 4.5^{\star}$ \\
\hline End systolic diameter/BSA [mm/m²] & $15.6 \pm 2.7$ & $15.4 \pm 4.2$ & $13.8 \pm 3.4^{*}$ & $18.3 \pm 4.0^{*}$ \\
\hline Left atrial diameter/BSA [mm/m²] & $21.9 \pm 2.3$ & $23.6 \pm 3.8^{\star}$ & $23.4 \pm 3.8$ & $24.0 \pm 3.9^{*}$ \\
\hline Left ventricular mass/BSA $\left[\mathrm{g} / \mathrm{m}^{2}\right]$ & $88 \pm 25$ & $133 \pm 38^{\ddagger}$ & $128 \pm 33^{\ddagger}$ & $142 \pm 46^{\ddagger}$ \\
\hline Pressure gradient peak; mean [mm Hg] & & & $90 \pm 18 ; 54 \pm 11$ & \\
\hline Aortic valve area; -index $\left[\mathrm{cm}^{2} ; \mathrm{cm}^{2} / \mathrm{m}^{2}\right]$ & & & $0.71 \pm 0.27 ; 0.38 \pm 0.12$ & \\
\hline Regurgitation aortic; mitral $\left[{ }^{\circ}\right]$ & & & & $2.8 \pm 0.3 ; 2.5 \pm 0.5$ \\
\hline Vena contracta aortal; mitral [cm] & & & & $0.70 \pm 0.17 ; 0.67 \pm 0.12$ \\
\hline
\end{tabular}

${ }^{*} p<0.05, \uparrow 0.01, \neq 0.001$ in comparison to controls. ACE - angiotensin-converting enzyme, ARB - angiotensin receptor blocker, BSA - body surface area, VHD - valvular heart disease

tolic filling. The frequencies of symptoms during stress tests, of ST-segment depression and of the combined parameter GRPT did not differ between patients with and without PRET.

Patients with VHD manifested higher values of hscTnT before and after stress than controls ( $p$ at least $<0.01$, Figure 1) without differences in patients with aortic stenosis and regurgitation. A small exercise-induced increase was found for hscTnT in patients with VHD $(p<0.01)$. Regression models revealed that $\mathrm{VO}_{2} \mathrm{AT}$ was predicted by baseline hscTnT ( $p=0.0194)$. PRET was predicted by the resting hscTnT value $(p=0.0028)$. Receiver-operator characteristics to predict PRET with hscTnT demonstrated an area under the curve of 0.689 (95\% Cl: 0.546-0.831), $p=0.015$. A hscTnT concentration of $6.96 \mathrm{pg} / \mathrm{ml}$ had a sensitivity of 0.696 and a specificity of 0.694 . In the subgroup with aortic stenosis, prediction of PRET by hsCTnT showed an area under the curve of 0.700 (95\% Cl: 0.529-0.871), $p=0.036$. The best cut-off value to predict PRET was 6.39 $\mathrm{pg} / \mathrm{ml}$, which had a sensitivity of 0.706 and a specificity of 0.667 .

\section{Postoperative functional outcome}

Fifty-two percent (32/61) of patients eventually underwent surgery. Of these, 6 patients were not able to perform the postoperative stress test (postoperatively, 1 patient died due to suspected acute ischemia, 1 suffered from a stroke, 2 from new atrial fibrillation, two patients reported progressive symptoms of heart failure). The remaining $26 \mathrm{pa}$ tients were reevaluated $535 \pm 340$ days after surgery. Echocardiographically, we observed a reduction of left ventricular mass index $\left(113 \pm 33 \mathrm{~g} / \mathrm{m}^{2} \mathrm{vs}\right.$. $145 \pm 46 \mathrm{~g} / \mathrm{m}^{2} ; p=0.0026$ ), and a borderline reduction of end diastolic diameter $\left(26.9 \pm 27.6 \mathrm{~mm} / \mathrm{m}^{2}\right.$ vs. $\left.29.4 \pm 4.6 \mathrm{~mm} / \mathrm{m}^{2} ; p=0.0511\right)$. Ejection fraction $(61.6 \pm 6.6 \%$ vs. $66.2 \pm 4.2 \% ; p<0.0001)$ and heart rate at rest $(69.1 \pm 11.5$ bpm vs. $77.3 \pm 12.3$ bpm; $p=0.0063)$ were lower after surgery but heart rate was higher after exercise $(130 \pm 16$ bpm vs. 122 \pm 19 bpm; $p=0.0449$ ), indicating greater chronotropic reserve. The number of patients with $\mathrm{VO}_{2} \%$ pred $<80 \%$ (cutoff for RET) was reduced from 15 to 7 ; $p=0.0483$. However, there was no improvement in the other single cardiopulmonary function param- 


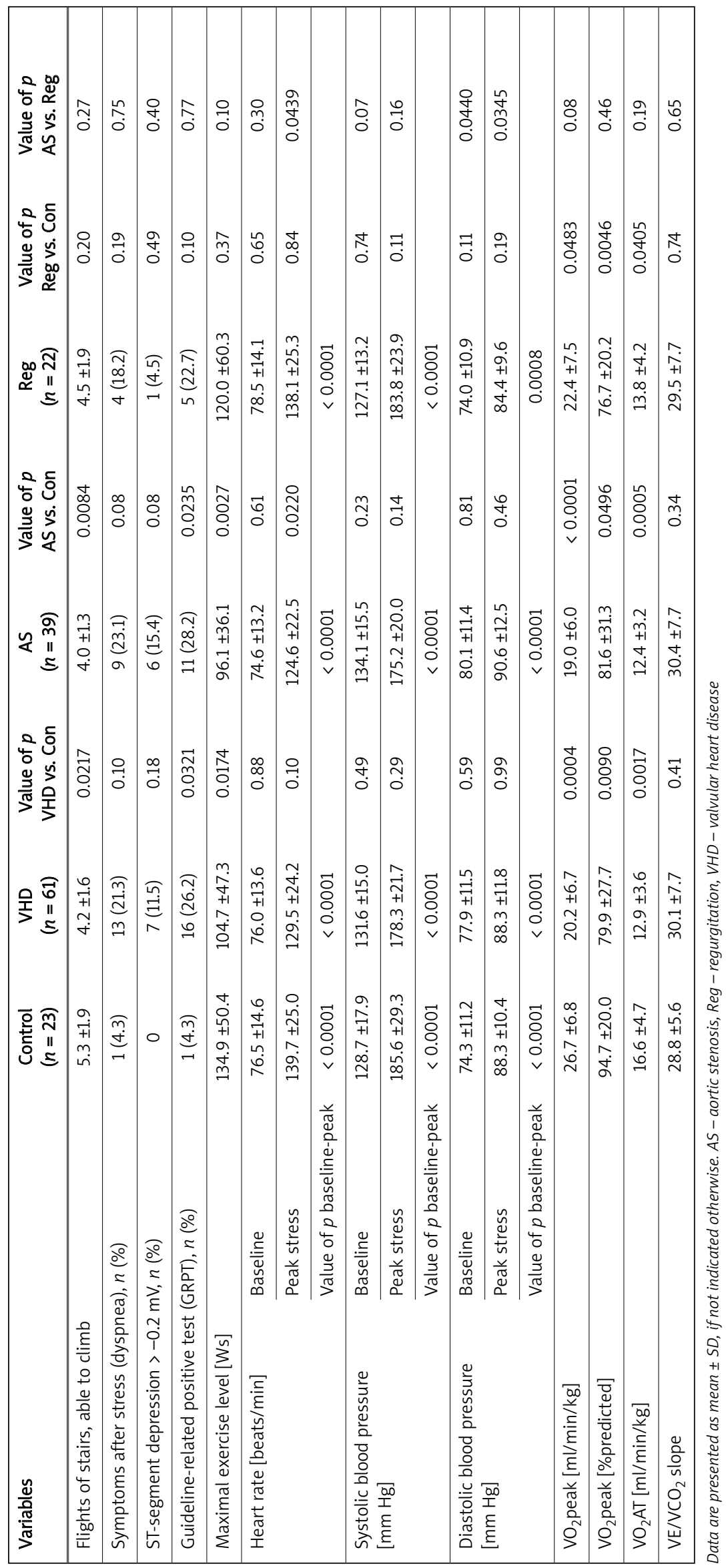




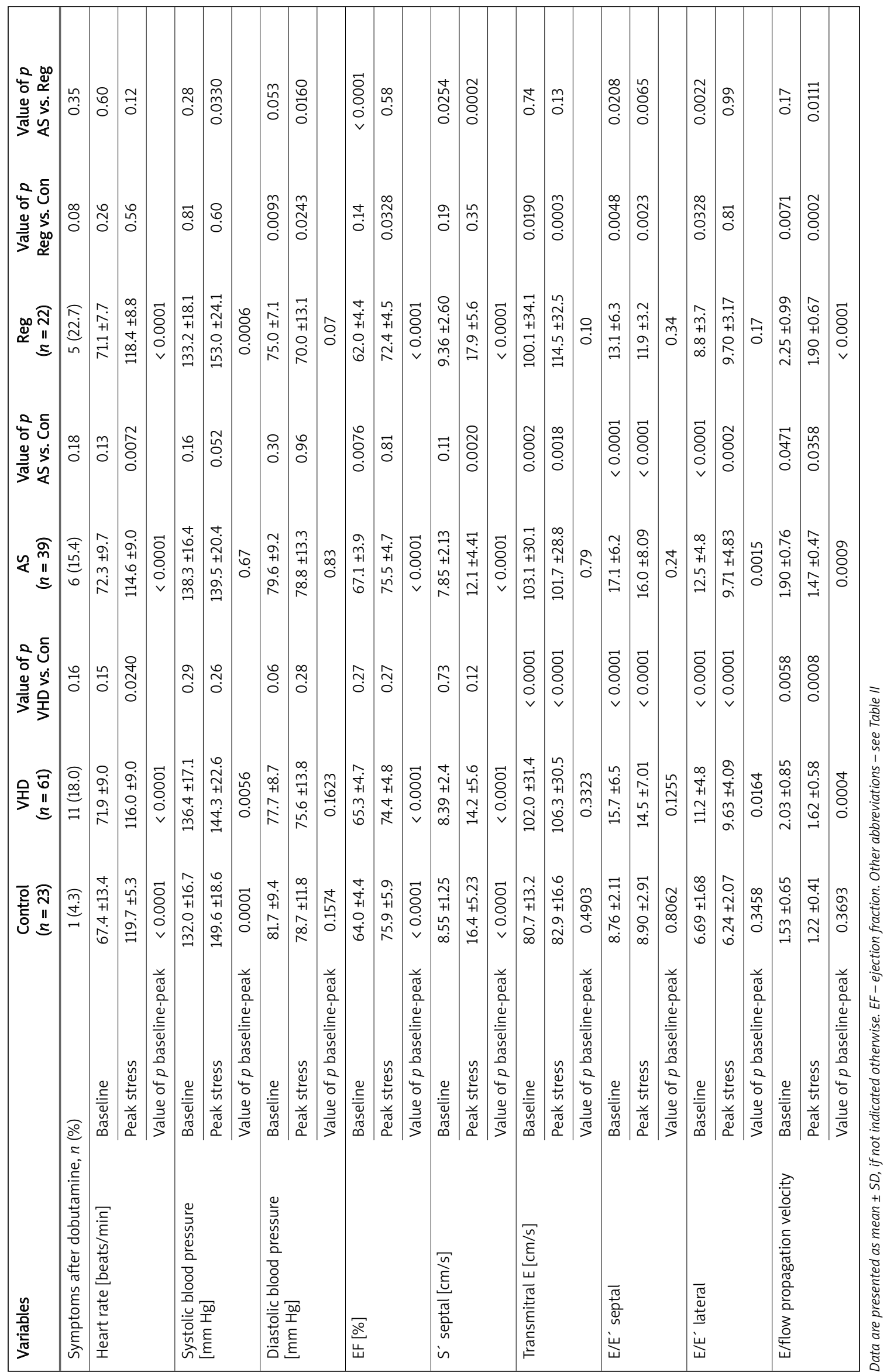


A

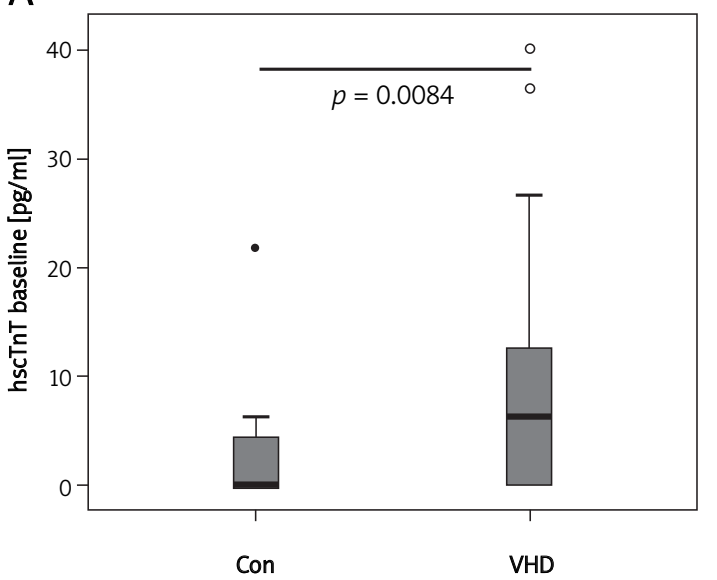

B

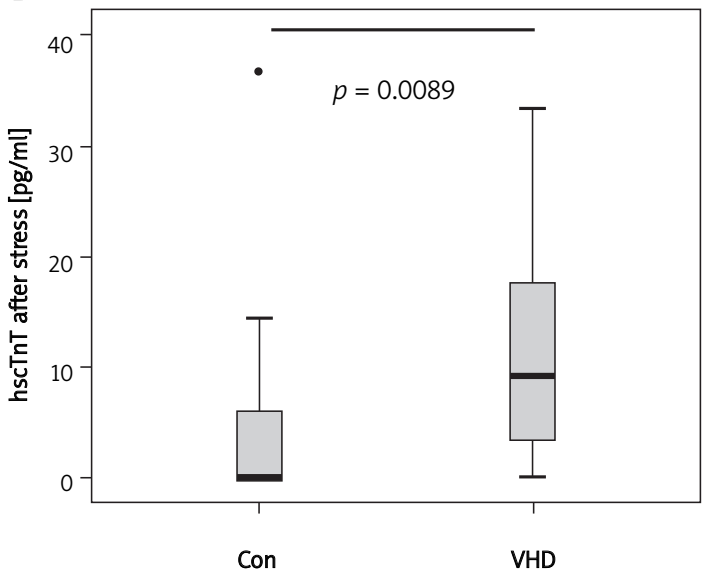

Figure 1. Box plots of high-sensitivity cardiac troponin T: A) before, B) after exercise in controls (Con) and patients with asymptomatic VHD. Significance given for log transformed values. Boxes represent quartiles with median (bold line), whiskers delineate $95 \%$ confidence interval, open circles show outliers (values more than 1.5 box lengths), asterisk shows extremes (values more than three box lengths)

eter after stress. The number of patients with PRET did not change significantly.

Preoperatively assessed $\mathrm{VO}_{2}$ pred predicted postoperative $\mathrm{VO}_{2}$ pred $\left(p=0.002, \beta=0.528, R^{2}=0.426\right)$ Preoperatively present PRET predicted postoperative left ventricular EF ( $p=0.022, \beta=0.448, R^{2}=$ $0.246)$ and remodeling (by mass index ( $p=0.040$, $\beta=0.545, R^{2}=0.425$ ) and end diastolic diameter index $(p=0.047))$. Baseline hscTnT predicted postoperative $\operatorname{EF}\left(p=0.022, \beta=0.451, R^{2}=0.246\right)$.

\section{Discussion}

Our data demonstrated that cardiopulmonary function testing and dobutamine stress echocardiography detected features of stress intolerance more often than a guideline-based bicycle stress test [1]. These data are in agreement with results in patients with asymptomatic mitral regurgitation [16] and extend them to other valvular lesions. Many of these findings are associated with elevated hscTnT values, which are known to have prognostic importance [17].

\section{Potential impact of stress tolerance on outcome}

Recent reviews and guidelines highlighted that studies are needed to evaluate the prognostic value of measures from exercise testing in patients with diastolic dysfunction/heart failure and preserved EF [18], especially in patients with VHD [19, 20]. Approximately $40 \%$ of our patients (group with PRET) showed a prognostically unfavorable feature of cardiopulmonary function [10-12]. In addition, abnormalities in pre-operative testing predicted the subsequent remodeling and cardiovascular function response in many patients. With the development of less invasive (e.g. transcatheter) proce- dures for valve replacements which possibly extend their indications, recently limited to very severe patients [21], these sorts of data should be valuable in helping to define subsets of patients with VHD who should be considered for earlier surgery.

\section{Role of hscTnT}

The finding that hscTnT was predictive for PRET in these patients was not unexpected. Elevations in hscTnT are sensitive to left ventricular hypertrophy and dilation [17]. In addition, stress-induced changes in troponin may be related to an acute stretch mechanism [22] or to integrin-mediated release [23]. Finally [22], elevations can occur with apoptosis, which has now been shown to be common in those with pathological hypertrophy [24, 25]. Regardless of mechanism, they suggest that an evaluative strategy might include hscTnT measurements.

\section{Role of systolic and diastolic function}

The group with PRET was more likely to have a reduced tissue Doppler $E^{\prime}$ in consistence with the exercise capacity data reported in patients with heart failure and preserved ejection fraction [26]. These data, including reduced transmitral E values, reflect deficient early diastolic left ventricular recoil in patients with heart failure and preserved EF [27]. There was no association with measures of elevated filling pressures and reduced contractile reserve, in contrast to other studies with heart failure and preserved EF $[28,29]$. However, there is controversy [30, 31]; perhaps the association develops later. Improvements in exercise tolerance induced by physical training were not associated with lower filling pressures as assessed by E/flow propagation velocity [32] or with diastolic function in a recent 
meta-analysis [33]. The contribution of contractile depression/blunted LV contractile reserve to exercise intolerance is also equivocal [27].

\section{Potential impact on clinical management}

Our data may be helpful in managing patients with asymptomatic VHD. First, they may help to define physical activities for professional and recreational lives. It is clear that objective limitations often exceed patient reported symptoms. In addition, those with prognostically relevant reductions in exercise and associated increases in hscTnT should be scrutinized carefully for symptoms. For patients with asymptomatic severe aortic stenosis it is known that more than $30 \%$ will have either an event or surgical therapy by one year [34]. Our data may be particularly helpful for patients with aortic regurgitation. They can be asymptomatic for long periods before clinical deterioration. A more objective assessment may be helpful in deciding when to suggest surgical intervention. New surgical techniques have shifted the risk-benefit ratio for patients with mitral regurgitation, allowing for earlier intervention [35]; and these techniques are now being applied to the aortic valve [36]. In the longer term, suggested exercise tests and biomarker evaluations may give the chance to optimize decision-making and to prevent further remodeling and functional deterioration in patients with asymptomatic VHD.

This is an exploratory, hypothesis-generating study, conducted in a single center on a limited number of patients.

In conclusion, among patients with asymptomatic moderate-severe VHD, spiroergometry as well as dobutamine stress echocardiography provide more sensitive detection of exercise intolerance than stress test criteria recommended in guidelines. In $39 \%$ of patients with VHD, the reduction of exercise tolerance occurred over a range of values associated in other studies with worse outcomes. This subgroup of patients can be detected by elevations in hscTnT. Additionally, preoperative exercise tolerance predicted postoperative exercise capacity, left ventricular remodeling and function, and hscTnT predicted postoperative EF. Our data suggest that exercise tolerance as well as hscTnT may be helpful in evaluating patients with asymptomatic VHD.

\section{Acknowledgments}

We are grateful to Carsten Schwenke, scossis, for statistical help. Kits for hscTnT were kindly provided by Roche Diagnostics, Germany.

\section{References}

1. Vahanian A, Alfieri O, Andreotti F, et al. Guidelines on the management of valvular heart disease (version 2012): The Joint Task Force on the Management of Valvular Heart
Disease of the European Society of Cardiology (ESC) and the European Association for Cardio-Thoracic Surgery (EACTS). Eur Heart J 2012; 33: 2451-96.

2. Schulz O, Rudolph A, Scheiner S, et al. Influence of acute and chronic myocardial loading conditions, function, structural changes and extracardiac factors on NT-proBNP in asymptomatic patients with preserved ejection fraction. Clin Res Cardiol 2011; 100: 57-65.

3. Gulati M, Black HR, Shaw LJ, et al. The prognostic value of a nomogram for exercise capacity in women. $N$ Engl J Med 2005; 353: 468-75.

4. Tabet JY, Beauvais F, Thabut G, JM T, Logeart D, CohenSolal A. A critical appraisal of the prognostic value of the VE/VCO2 slope in chronic heart failure. Eur J Cardiovasc Prevention Rehab 2003; 10: 267-72.

5. Schiller NB, Shah PM, Crawford M, et al. Recommendations for quantitation of the left ventricle by two-dimensional echocardiography. American Society of Echocardiography Committee on Standards, Subcommittee on Quantitation of Two-Dimensional Echocardiograms. J Am Soc Echocardiogr 1989; 2: 358-67.

6. Ganau A, Devereux RB, Roman MJ, et al. Patterns of left ventricular hypertrophy and geometric remodeling in essential hypertension. J Am Coll Cardiol 1992; 19: 1550-8.

7. Ommen SR, Nishimura RA, Appleton CP, et al. Clinical utility of Doppler echocardiography and tissue Doppler imaging in the estimation of left ventricular filling pressures: a comparative simultaneous Doppler-catheterization study. Circulation 2000; 102: 1788-94.

8. Moller JE, Sondergaard E, Seward JB, Appleton CP, Egstrup K. Ratio of left ventricular peak E-wave velocity to flow propagation velocity assessed by color $\mathrm{M}$-mode Doppler echocardiography in first myocardial infarction: prognostic and clinical implications. J Am Coll Cardiol 2000; 35: 363-70.

9. lung B, Gohlke-Barwolf C, Tornos P, et al. Recommendations on the management of the asymptomatic patient with valvular heart disease. Eur Heart J 2002; 23: 1252-66.

10. Mancini DM, Eisen H, Kussmaul W, Mull R, Edmunds LH Jr, Wilson JR. Value of peak exercise oxygen consumption for optimal timing of cardiac transplantation in ambulatory patients with heart failure. Circulation 1991; 83: 778-86.

11. Gitt AK, Wasserman K, Kilkowski C, et al. Exercise anaerobic threshold and ventilatory efficiency identify heart failure patients for high risk of early death. Circulation 2002; 106: 3079-84.

12. Guazzi M, Myers J, Arena R. Cardiopulmonary exercise testing in the clinical and prognostic assessment of diastolic heart failure. J Am Coll Cardiol 2005; 46: 1883-90.

13. Haluska BA, Short L, Marwick TH. Relationship of ventricular longitudinal function to contractile reserve in patients with mitral regurgitation. Am Heart J 2003; 146: 183-8.

14. Monin JL, Monchi M, Gest V, Duval-Moulin AM, DuboisRande JL, Gueret P. Aortic stenosis with severe left ventricular dysfunction and low transvalvular pressure gradients: risk stratification by low-dose dobutamine echocardiography. J Am Coll Cardiol 2001; 37: 2101-7.

15. Sohn DW, Chai IH, Lee DJ, et al. Assessment of mitral annulus velocity by Doppler tissue imaging in the evaluation of left ventricular diastolic function. J Am Coll Cardiol 1997; 30: 474-80.

16. Messika-Zeitoun D, Johnson BD, Nkomo V, et al. Cardiopulmonary exercise testing determination of functional capacity in mitral regurgitation: physiologic and outcome implications. J Am Coll Cardiol 2006; 47: 2521-7. 
17. de Lemos JA, Drazner MH, Omland T, et al. Association of troponin $\mathrm{T}$ detected with a highly sensitive assay and cardiac structure and mortality risk in the general population. JAMA 2010; 304: 2503-12.

18. Arena R, Sietsema KE. Cardiopulmonary exercise testing in the clinical evaluation of patients with heart and lung disease. Circulation 2011; 123: 668-80.

19. Bjarnason-Wehrens B, Schulz O, Gielen S, et al. Leitlinie körperliche Aktivität zur Sekundärprävention und Therapie kardiovaskulärer Erkrankungen. Clin Res Cardiol 2009; 4: 1-44.

20. Arena R, Myers J, Williams MA, et al. Assessment of functional capacity in clinical and research settings: a scientific statement from the American Heart Association Committee on Exercise, Rehabilitation, and Prevention of the Council on Clinical Cardiology and the Council on Cardiovascular Nursing. Circulation 2007; 116: 329-43.

21. Akin I, Kische S, Rehders TC, et al. Indication for percutaneous aortic valve implantation. Arch Med Sci 2010; 6: 296-302.

22. Feng J, Schaus BJ, Fallavollita JA, Lee TC, Canty JM Jr. Preload induces troponin I degradation independently of myocardial ischemia. Circulation 2001; 103: 2035-7.

23. Hessel MH, Atsma DE, van der Valk EJ, Bax WH, Schalij MJ, van der Laarse A. Release of cardiac troponin I from viable cardiomyocytes is mediated by integrin stimulation. Pflugers Arch 2008; 455: 979-86.

24. Taniike M, Yamaguchi O, Tsujimoto I, et al. Apoptosis signal-regulating kinase $1 /$ p38 signaling pathway negatively regulates physiological hypertrophy. Circulation 2008; 117: 545-52.

25. Liu Q, Sargent MA, York AJ, Molkentin JD. ASK1 regulates cardiomyocyte death but not hypertrophy in transgenic mice. Circ Res 2009; 105: 1110-7.

26. Chattopadhyay S, Alamgir MF, Nikitin NP, Rigby AS, Clark AL, Cleland JG. Lack of diastolic reserve in patients with heart failure and normal ejection fraction. Circ Heart Fail 2010; 3: 35-43.

27. Paulus WJ. Culprit mechanism(s) for exercise intolerance in heart failure with normal ejection fraction. J Am Coll Cardiol 2010; 56: 864-6.

28. Skaluba SJ, Litwin SE. Mechanisms of exercise intolerance: insights from tissue Doppler imaging. Circulation 2004; 109: 972-7.

29. Borlaug BA, Olson TP, Lam CS, et al. Global cardiovascular reserve dysfunction in heart failure with preserved ejection fraction. J Am Coll Cardiol 2010; 56: 845-54

30. Kitzman DW, Higginbotham MB, Cobb FR, Sheikh KH, Sullivan MJ. Exercise intolerance in patients with heart failure and preserved left ventricular systolic function: failure of the Frank-Starling mechanism. J Am Coll Cardiol 1991; 17: 1065-72.

31. Maeder MT, Thompson BR, Brunner-La Rocca HP, Kaye DM. Hemodynamic basis of exercise limitation in patients with heart failure and normal ejection fraction. J Am Coll Cardiol 2010; 56: 855-63.

32. Freimark D, Adler Y, Feinberg MS, et al. Impact of left ventricular filling properties on the benefit of exercise training in patients with advanced chronic heart failure secondary to ischemic or nonischemic cardiomyopathy. Am J Cardiol 2005; 95: 136-40.

33. Holland DJ, Kumbhani DJ, Ahmed SH, Marwick TH. Effects of treatment on exercise tolerance, cardiac function, and mortality in heart failure with preserved ejection fraction a meta-analysis. J Am Coll Cardiol 2011; 57: 1676-86.
34. Rosenhek R, Binder T, Porenta G, et al. Predictors of outcome in severe, asymptomatic aortic stenosis. N Engl J Med 2000; 343: 611-7.

35. Fedak PW, McCarthy PM, Bonow RO. Evolving concepts and technologies in mitral valve repair. Circulation 2008; 117: 963-74.

36. Aicher D, Holz A, Feldner S, Kollner V, Schafers HJ. Quality of life after aortic valve surgery: Replacement versus reconstruction. J Thorac Cardiovasc Surg 2011; 142: e19-24. 